\title{
A comparative Study for Designing an Efficient Intelligence System for the Process of Discrimination
}

\author{
Iman S. Mohammed \\ Computer Science Department \\ College of Computer Science and \\ Mathematics \\ University of Mosul, Iraq \\ ImanSubhi@uomosul.edu.iq \\ DOI: $\underline{10.33899 / \text { edusj.1970.163336 }}$
}

\author{
Shatha A. Mohammed \\ Software Engineering Department \\ College of Computer Science and \\ Mathematics \\ University of Mosul, Iraq \\ ShathaAbdullah@uomosul.edu.iq
}

\begin{abstract}
Face recognition is one of the most important biometrics techniques used to identify people. The research aims to build an efficient system by devising a new method of discrimination that includes advanced image processing techniques and intelligent techniques.

This work has been implemented in several stages, the first of which is the arrangement of the database, Followed by pre-processing based on the integration of Gaborand DCT conversion. And then adopt two methods in extracting statistical features, the first dependent first-class statistics, the second dependent second-class statistics of the GLCM matrix and then draw the important features of them.

In the phase of discrimination, two types of artificial neural networks were used after their construction in the 2016 MATLAB environment, BPNN and Elman. Finally, the efficiency of the methods used and the identification of the best were compared.
\end{abstract}

Key words:_Face Recognition, Gabor filters, Discrete Cosine Transform (DCT), BPNN, Elman NN, statistical features SF. 
دراسة مقارنة لتصميم نظام ذكائي كفوي لعملية التمييز

$$
\begin{aligned}
& \text { شذى عبدالله محمد } \\
& \text { قسم هندسة البرمجيات } \\
& \text { كلية علوم الحاسوب والرياضيات } \\
& \text { العراق/ جامعة الموصل }
\end{aligned}
$$

ShathaAbdullah@uomosul.edu.iq

DOI: $\underline{10.33899 / \text { edusj.1970.163336 }}$

$$
\begin{aligned}
& \text { ايمان صبحي محمد } \\
& \text { قسم علوم الحاسوب } \\
& \text { كلية علوم الحاسوب والرياضيات } \\
& \text { العراق/ جامعة الموصل }
\end{aligned}
$$

القبول

$2018 / 12 / 03$
الاستلام

$2018 / 10 / 07$

\section{الخلاصة}

يُعد تمييز الوجوه من أهم تقنيات المقاييس الحيوية المستعلة في التعرف على الأشخاص. يهاف البحث الى بناء نظام كفوء من خلا ابتكار أسلوب جديد في التمييز يضم تقنيات معالجة الصور المتقدمة والتقنيات الأكائية.

تم تطبيق العمل بعدة مراحل متسلسلة, أولها ترتيب قاعدة البيانات, تليها عملية المعالجة الأولية المعتمدة على الدمج بين مرشحات جابور وتحويل الجيب تمام المتقطع (DCT) .ومن ثم اعتماد طريقتين في استخلاص الميزات الإحصائية, الاولى تعتمد احصائيات الارجة الأولى, الثانية تعتمد احصائيات الارجة الثانية لمصفوفة GLCM ومن ثم استخلاص الميزات المهمة منها.

في مرحلة التمييز تم استعمال نوعين من الثبكات العصبية الاصطناعية حيث تم بناءهما في بيئة ماتلاب2016 و هما BPNN و Elman. واخيراً تم مقارنة كفاءة الطرائق المستعملة وتحديد الأفضل.

الكلمات المفتاحية:_تمييز الوجوه, مرشحات جابور , تحويل الجيب تمام المتقطع, الثبكة العصبية ذات التغذية العكسية, الثبكة العصبية ايلمان, الصفات الاحصائية.

تعددت وسائل واساليب تمييز المقاييس الحيوية,لكن المنتشر على نطاق واسع هي بصمات

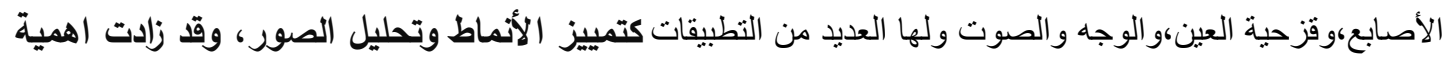
تقنية تمييز الوجوه بثكل كبير بسبب استعماله الواسع في التطبيقات التجارية و التطبيقات القانونية في تحديد الهوية في الطب الثرعي ، والتحكم في الوصول (التوثق من الاثخاص المخولين للوصول اللى معلومات وبيانات معينة)، ومراقبة الحدود، والمراقبة بالفيديو، والخدمات المصرفية الإكترونية الآمنة، 
هنالك مقاييس حيوية مختلفة يمكن أن تستعمل لغرض تمييز الأثخاص مثل بصمة الإصبع وبصمة

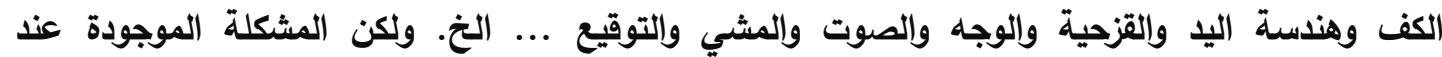
استعمال بصمة الإصبع و القزحية و بصمة الكف و الصوت و المشي في التمييز انه في هذه الطرائق نحتاج

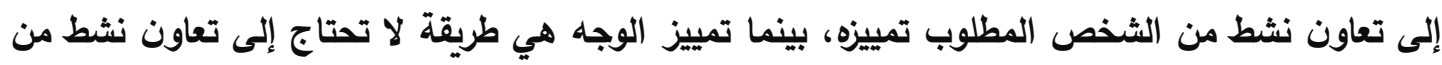
الثخص اذ ممكن تمييز الثخص من خلال مقطع فديو مسجلومن دون اعلامه. هنالك نوعان من انظمة تمييز الوجه:1- نظام التحقق verification system (مطابقة واحد الى واحد). 2- نظام تحديد الهوية identification system (مطابقة واحد الى عدة).

وان طرائق تمييز الوجوه تقسم إلى ثلاثة أنواع:-

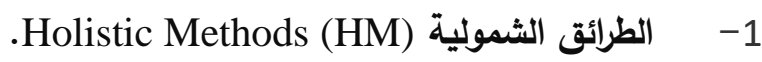

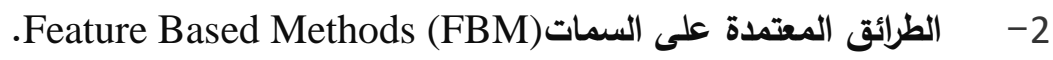

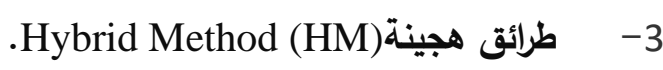

اذ قام كل من الباحثان Raqdir و RenuDhir عام (2017) باقتراح طريقة هجينة لتمييز الوجه, كما قام Essam H. Mageed مع مجموعة باحثين عام (2017) باقتراح نظام لتمييز الوجه، و مسبقاً قدم الباحث Nawaf H. Barnouti مع مجموعة باحثين عام (2016) باقتراح نظام لكثف و تمييز الوجها.

2- 2 الخوارزميات المستعملة

تم استعمال اساليب مختلفة في معالجة الصور لتبسيطها واستخلاص الصفات الجيدة منها فضلا عن استعمال الثبكات العصبية في التمييز.وفيما يلي تفصيل للمرشحات التي تم تطبيقها على الصور,

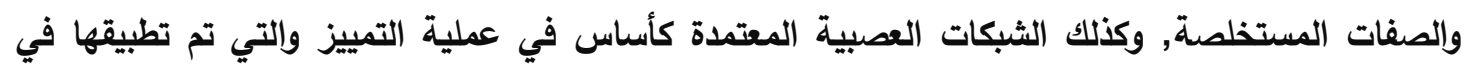

Statistical Features (SF) الصفات الاحصائية وتعد المقاييس الاحصائية (SF) من الادوات الفعالة والتي تستعمل بثكل واسع في مجال المعالجة

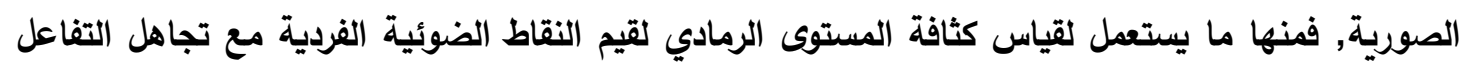
المكاني بين نقاط الصورة, وتمثل احصاءات الارجة الاولى, ومنها ما يستعمل لقياس كثافة المستوى الرمادي

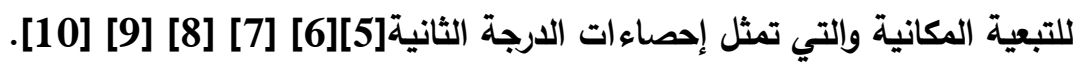

$$
\begin{aligned}
& \mu_{m n}=\frac{1}{m^{*} n} \sum_{x=0}^{M-1} \sum_{y=0}^{N-1} t(x, y) \\
& \sigma_{m n}=\left(\frac{1}{m * n} \sum_{x=0}^{M-1} \sum_{y=0}^{N-1}\left(t(x, y)-\mu_{m n}\right)^{2}\right)^{1 / 2} \\
& \text { N } M
\end{aligned}
$$

(احصاء ات الدرجة الاولى (SF1) 


$$
\text { skewness }=\frac{1}{N}\left(\frac{\sum_{i-1}^{N}\left(X_{i}-\bar{X}\right)^{3}}{\sigma^{3}}\right)
$$

احصاء) الدرجة الثانية(SF2)

$$
\begin{aligned}
& \text { Energy }=\sum_{i} \sum_{j} p_{d}^{2}(i, j) \\
& \text { Contrast }=\sum_{i} \sum_{j}(i-j)^{2} p(i, j) \\
& \text { Correlation }=\frac{\sum_{i} \sum_{j}\left(i-\mu_{x}\right)\left(j-\mu_{y}\right) p(i, j)}{\sigma_{x} \sigma_{y}} \\
& \text { AngularSecondMoment }=\sum_{i} \sum_{j} \frac{p(i, j)}{1+i-j}
\end{aligned}
$$$$
\text { 3) (3 الارتباط: - (3) }
$$

2-2 مرشح جابور)Gabor Filter(GF

يعرف مرشح Gabor على أنه " مجموعة من المويجات، مع كل مويجة تلتقط الطاقة بتردد معين

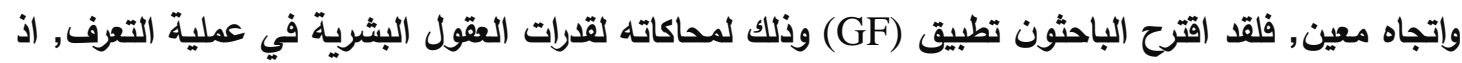

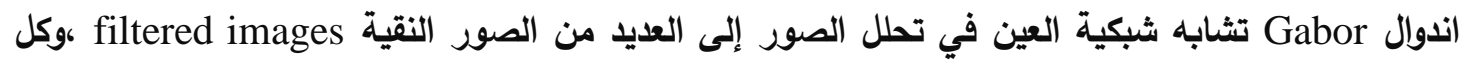
منها يتضمن كثافات متفاوتة على نطاق ضيق من الترددات والاتجاهات، ويكون (GF) ذا البعدين في المجال المكاني بشكل(Gaussian Kernal Function) مضمن بواسطة الموجة الجييية، وقد استعمل هذا المرشح في وني

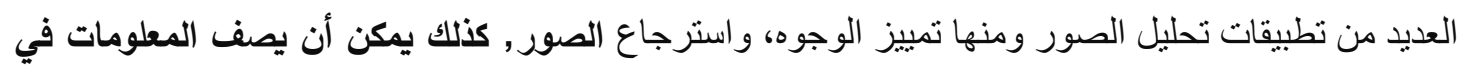
الترددات الواطئة والمتوسطة بثكل جيد، وايضاً يستعمل في المجالين التردي والمكاني لذا يكون هذا المرشح مجالا مرنا؛ لامتلاكه صفة التعدد في الاتجاهات والقياس؛ لذلك يمكن استعمال صفة التعدد في مرحلة

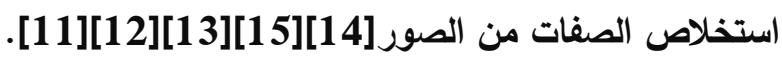
Complex تتضمن أجزاء حقيقية وأجزاء خيالية والتي يمكن صياغتها باستعمال function

Complex:

$g(x, y ; \lambda, \theta, \Psi, \sigma, \gamma)=\exp \left(-\frac{x^{\prime 2}+\gamma^{2} y^{\prime 2}}{2 \sigma^{2}}\right) \exp \left(i\left(2 \pi \frac{x^{\prime}}{\lambda}+\psi\right)\right)=g_{R}+i g_{I}$

Real:

$g_{R}(x, y ; \lambda, \theta, \Psi, \sigma, \gamma)=\exp \left(-\frac{x^{\prime 2}+\gamma^{2} y^{\prime 2}}{2 \sigma^{2}}\right) \cos \left(2 \pi \frac{x^{\prime}}{\lambda}+\psi\right)$

Imaginary:

$g_{I}(x, y ; \lambda, \theta, \Psi, \sigma, \gamma)=\exp \left(-\frac{x^{\prime 2}+\gamma^{2} y^{\prime 2}}{2 \sigma^{2}}\right) \sin \left(2 \pi \frac{x^{\prime}}{\lambda}+\psi\right)$ 


$$
\begin{aligned}
& \text { حيث إن: ( } y^{\prime}=-x \sin \theta+y \cos \theta \quad x^{\prime}=x \cos \theta+y \sin \theta \\
& \text { ג : تمثل الطول الموجي لعامل الجيبية. } \\
& \text { o } \\
& \text { 世 : الإزاحة في كل مرحلة. } \\
& \text { o }
\end{aligned}
$$

Discrete Cosine Transform(DCT) 3-2 طريقة الجيب تمام المتقطع ان تحويل الجيب تمام المتقطع هو تحول خطي يرتبط ارتباطاً وثيقاً بتحويل فورييه المتقطع Transform Discrete Fourier (DFT)

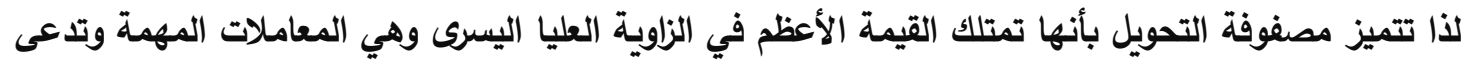
Amplitude-Coefficients (AC) المهملة) (Discrete-Coefficients (DC) والمعادلة (4) ادناه توضح تحويل الجيب تمام المتقطع ثنائي

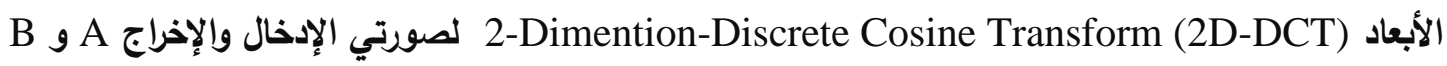
على التوالي, وإن Nو $M$ و تمثل أبعاد الصورة [16][17]. $\left.B(m, n)=u(m) u(n) 2 / N \sum_{i=0}^{M-1} \sum_{j=0}^{N-1} A(i, j)(\cos (2 i+1) m \pi / 2 M)\right)(\cos (2 j+1) n \pi / 2 N) \ldots .(4)$ $m=0,1,2,----M-1$ $n=0,1,2,----N-1$ $u(m)=u(n)=1 / \sqrt{2} \ldots . m, n=0$ $u(m)=u(n)=1 \ldots . m, n \neq 0$

4-2 الثبكات العصبية الاصطناعية ANN) Artificial Neural Networks وتعد الثبكات العصبية الاصطناعية من تقنيات الذكاء الاصطناعي, متمثلة بنموذج رياضي يحاكي الثبكات العصبية البايولوجية, حيث أن عدد عقد الإذخال تكون بعدد الصفات المستخلصة من الصورة، أما عدد عقد الإخراج فتمثّل عدد الأصناف المطلوب تمييزها بالشبكات العصبية المستعملة [18], وإلشكل (1) يوضح الهيكل العام للشبكات العصبية، في حين يختلف عدد العقد في الطبقات المخفية من شبكة إلى أخرى

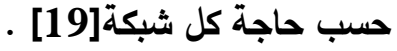

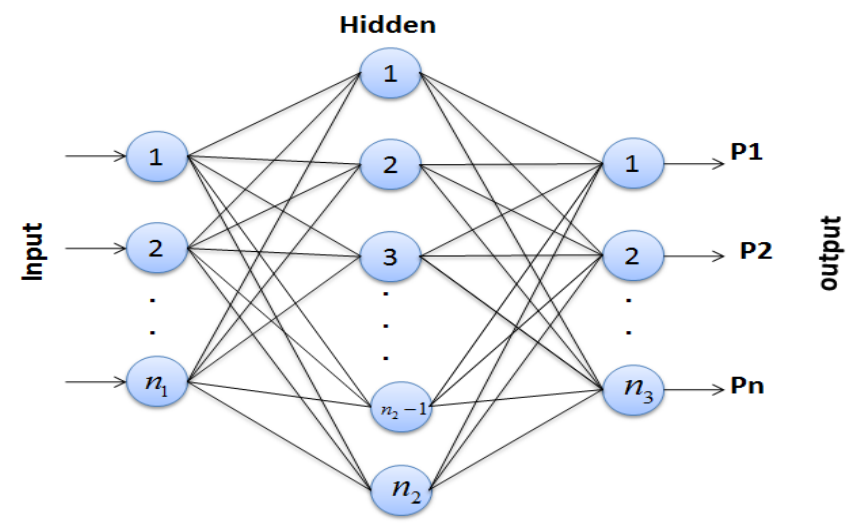


n1 n : تمثل عدد خلايا الإذخال.

n2 : تمثل عدد خلايا الطبقة المخفية.

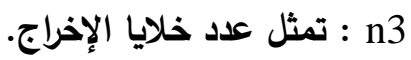

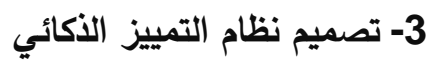

في هذا البحث تم تصميم النظام لتمييز الوجوه, ولان كل نظام تمييز بثكل عام يتكون من خطوات

اساسية تم استعمالها في هذا البحث وكما موضحة بالثكل(2).

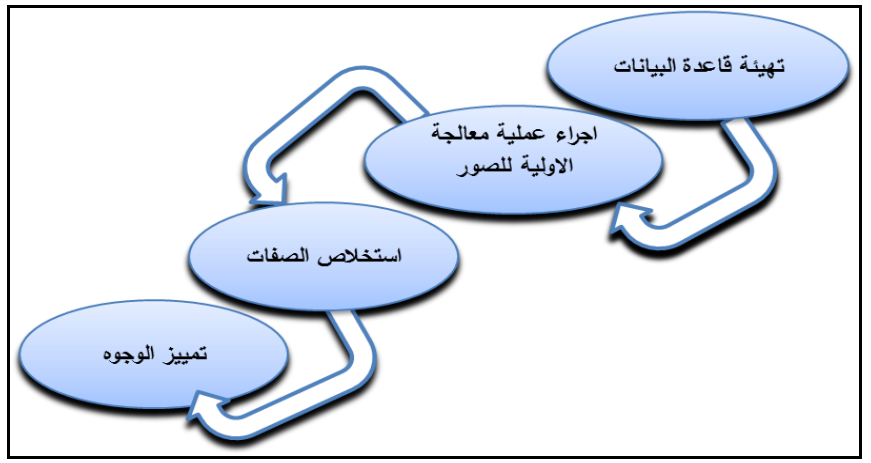

الشكل(2) المخطط العام للبحث

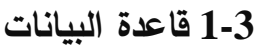

تم استعمال قاعدة بيانات مؤلفة من 270 صورة لعشرة أشخاص تمثل أصناف التمييز بالثبكة العصبية لاحقا, حيث كان لكل شخص (27) صورة مختلفة وبحالات متعددة, قسمت الى 220 صورة للتدربب بنسبة22 صورةلكل شخص و50 صورة للاختبار بنسبة 5 صور لكل شخص, والثكل(3) يوضح عينات من الأصناف العشرة من قاعدة البيانات.

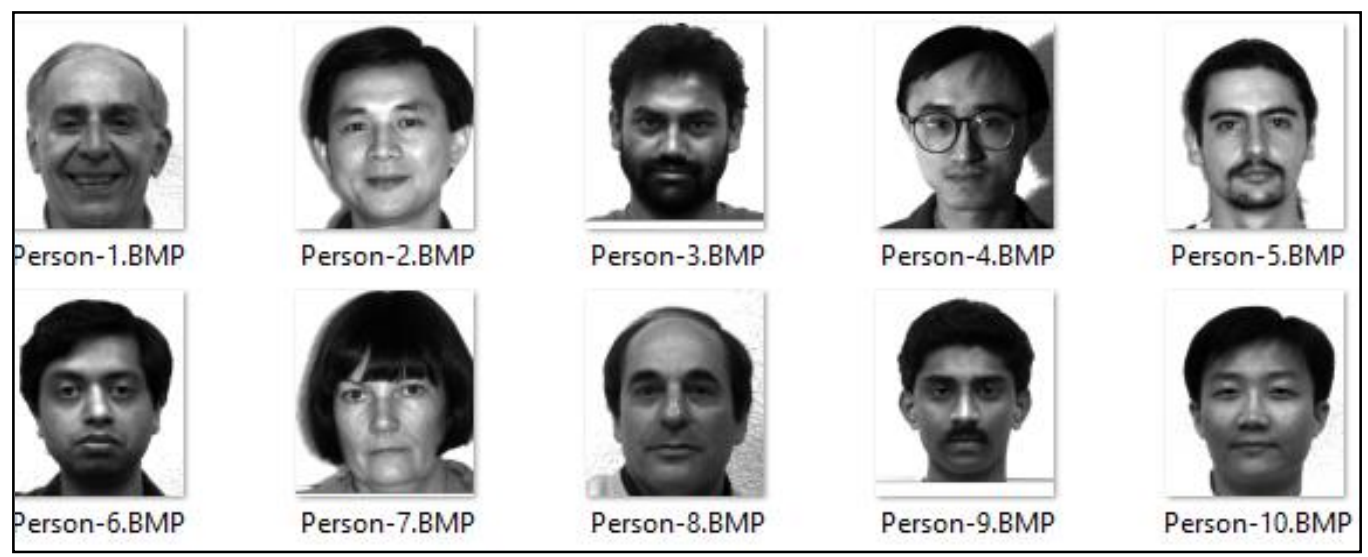

الثكل (3) مجموعة قاعدة البيانات

2-3 المعالجة الأولية للصور

تتضمن هذه المرحلة إجراء عملية معالجة أولية للصور بتطبيق المرشحات على صور قاعدة البيانات, وهذه المرشحات هي: 
Gabor Filters (GF) اولا: مرشحات جابور

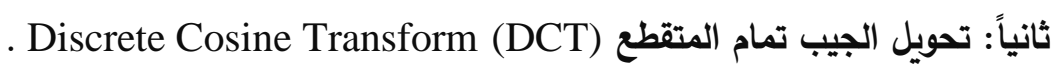
كما تتضمن هذه المرحلة خطوات معالجة الصور الرقمية والمطبقة على الصورة الداخلة إلى النظام لإجراء المعالجة الأولية وتتضمن الخطوات الاتية: 1. قراءة الصور.

2. تحويلها إلى صور رمادية (في حال كونها ملونه). 3. إخضاع الصورة لمرشحات Gabor المتعدةة؛ لتحويل الصورة من الحيّز المكاني إلى الحيّز التردئ.

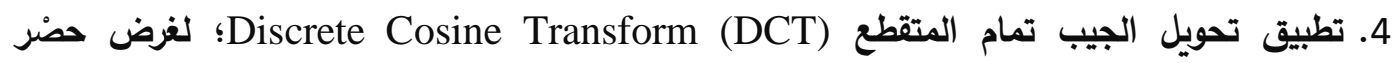
المعاملات التي تحتوي على طاقة عالية في الزاوية اليسرى العليا من الصورة. ويوضح المخطط الانسيابي في الشكل (4) تسلسل خطوات تطبيق مرشحات Gabor GF) على الصورة.

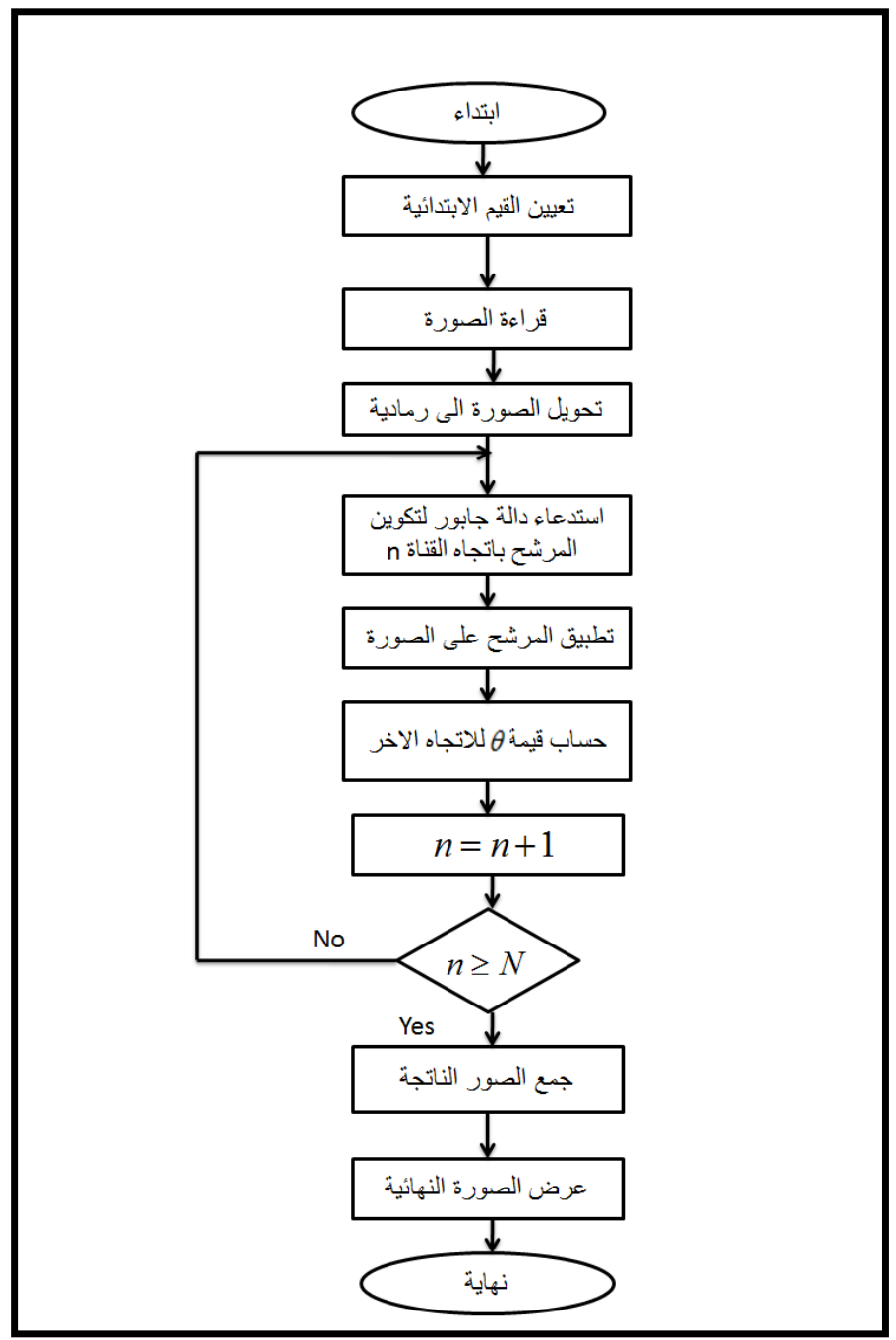

شكل (4) المخطط الانسيابي لخطوات تطبيق مرشحات Gabor 
(FE) Features Extraction 3-3 استخلاص الصفات تتضمن هذه المرحلة إجراء عملية استخلاص السمات(FE) للصور التي تم معالجتها في الخطوة السابقة, وتتضمن هذه العملية اعتماد أسلوبين مختلفين, وكما موضح بالفقرتين التاليتين:

1-3-3 - 1-3 - 1اسلوب الاول

استخلاص الصفات الإحصائية من الارجة الأولى (SF1), حيث يتم تقطيع الصورة الناتجة من عملية المعالجة الاولية من (3-2) الى (4) مقاطع متساوية, واخذ الجزء الاعلى من الجانب الايسر للصورة والذي يضمن التركيز على معاملات الطاقة العالية واعتماده كصورة جديدة باستعمال تحويل (DCT). ويتم بعدها تقطيع الصورة الجديدة الى (9) مقاطع, وذلك للتركيز على كل معاملات اجزاء الصورة بالتساوي, ولكلّ

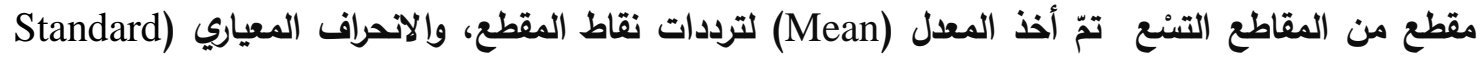
(deviation)، والعزم الثالث "الميل" (Skewness) ليصبح مجموع الصفات الكلي 27 صفة لكل صورة, والثكل (5) يوضح مخطط التقطيع واستخلاص الصفات.

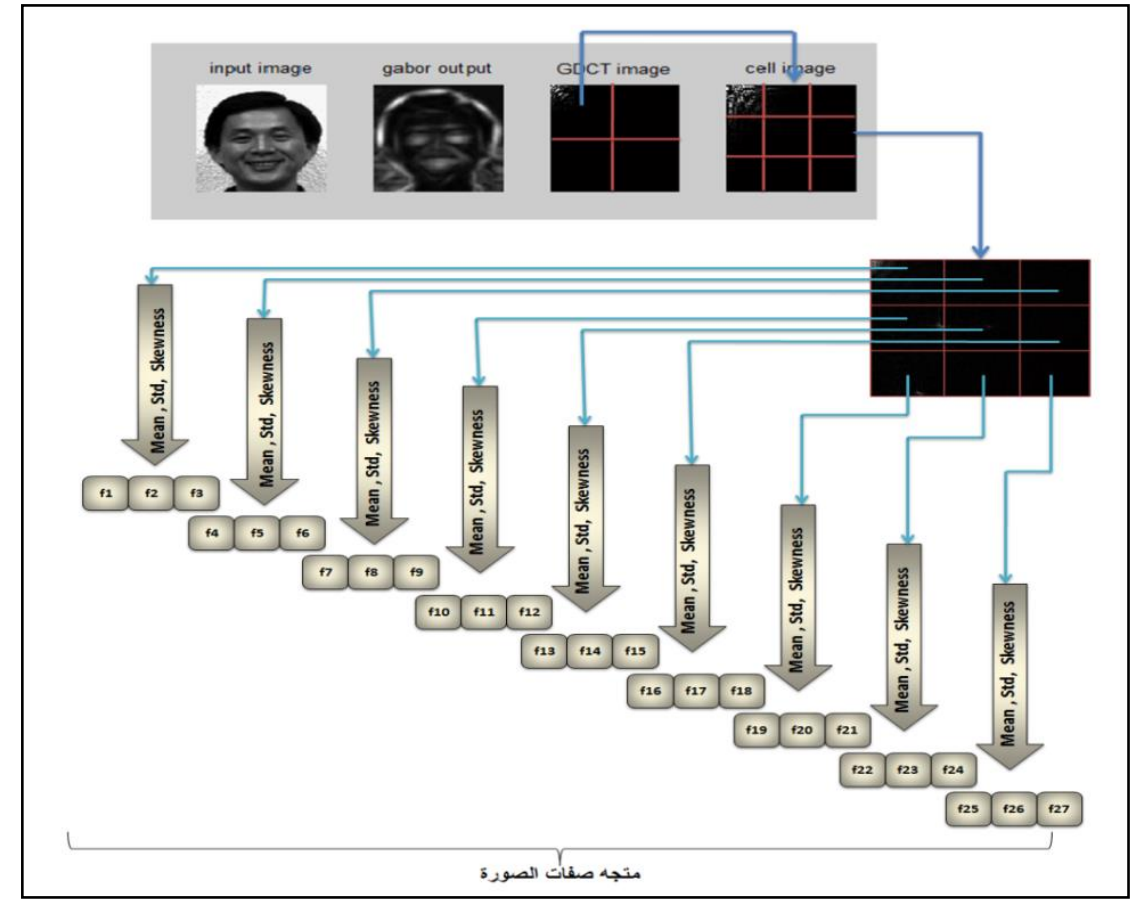

SF1 شكل (5) مخطط التقطيع واستخلاص الصفات الاحصائية

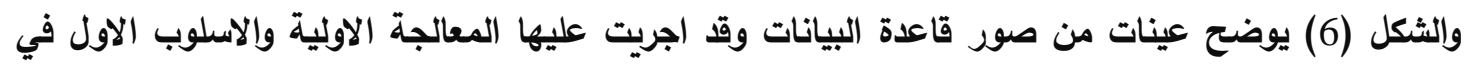
التقطيع واستخلاص الصفات. 
دراسة مقارنة لتصميم نظام ذكائي كفوي لعملية التمييز

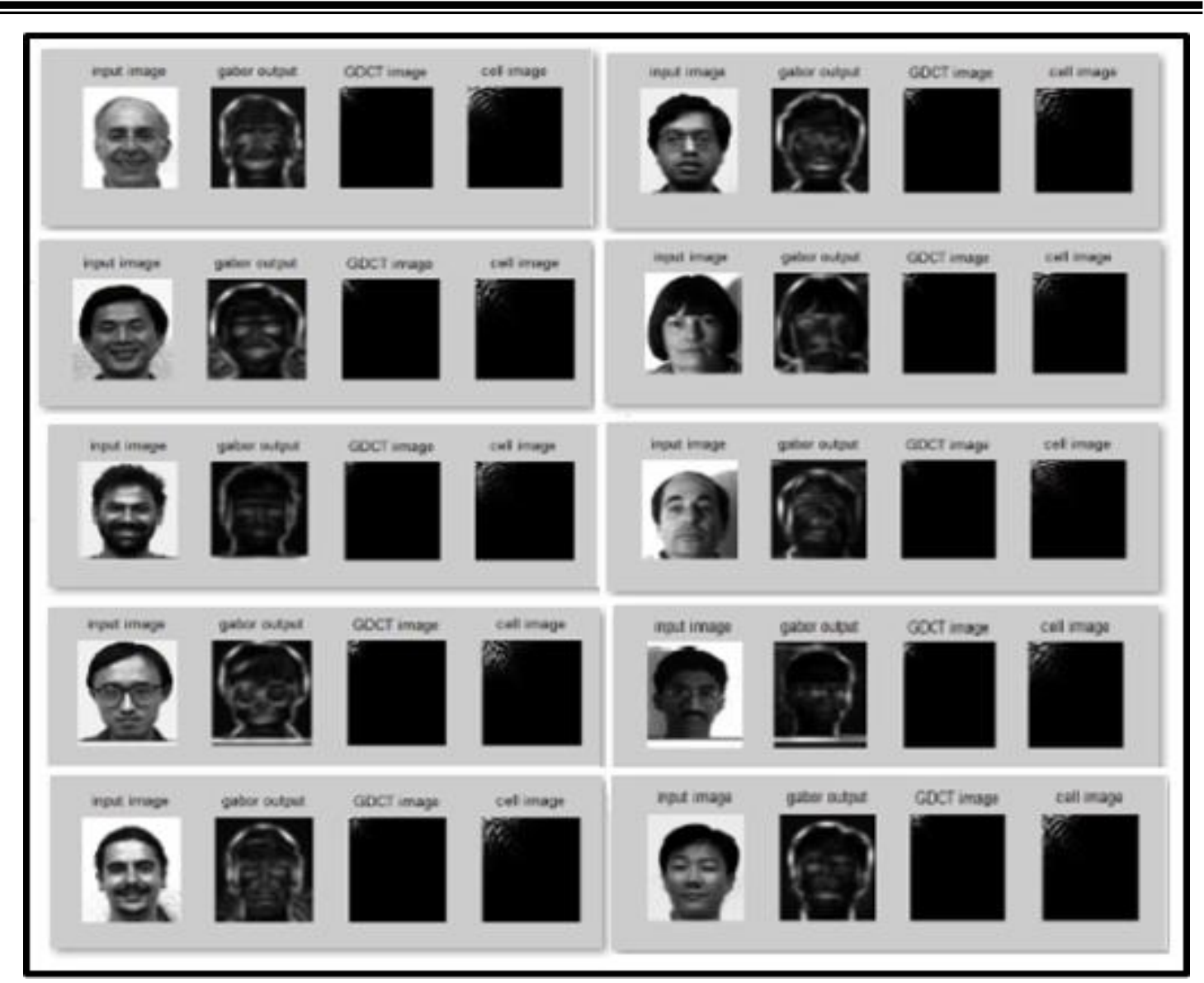

شكل (6) المعالجة الاولية والتقطيع بالأسلوب الاول لعينات من صور الاشخاص

$$
\text { 2-3-3 2-3 الاسلوب الثاني }
$$

ويتضمن هذا الاسلوب اعتماد الصور الناتجة من عملية المعالجة الاولية, لاستخلاص الصفات الإحصائية من الارجة الثانية (SF2) مباشرةً وبدون اجراء أية عملية تقطيع, حيث يتم حساب مصفوفة التبعية المكانية في تواجد المستوى الرمادي Grix ) Gray-Level Co-occurrence Matrix) التي تعطي معلومات عن التردد النسبي لمواقع أزواج القيم الرمادية المتجاورة بمسافة تمثل عدد من نقاط الصورة وبقيمة زاوية ر, ثم يتم استخلاص أربع صفات مهمة هي الطاقة, التباين, الارتباط, والتجانس. والثكل (7) يبين خطوات هذا الأسلوب. 


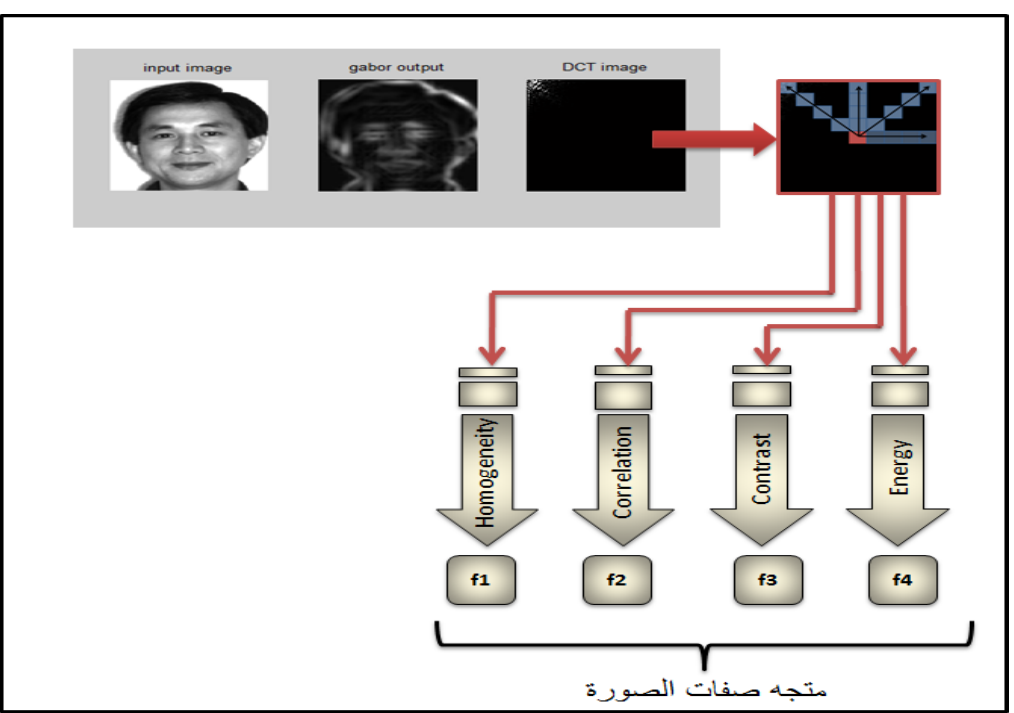

شكل (7) مخطط استخلاص الصفات الاحصائية FE2

والثكل (8) يوضح عينات من صور قاعدة البيانات التي أُجريت عليها المعالجة الأولية والأسلوب الثاني في الأية استخلاص الصفات

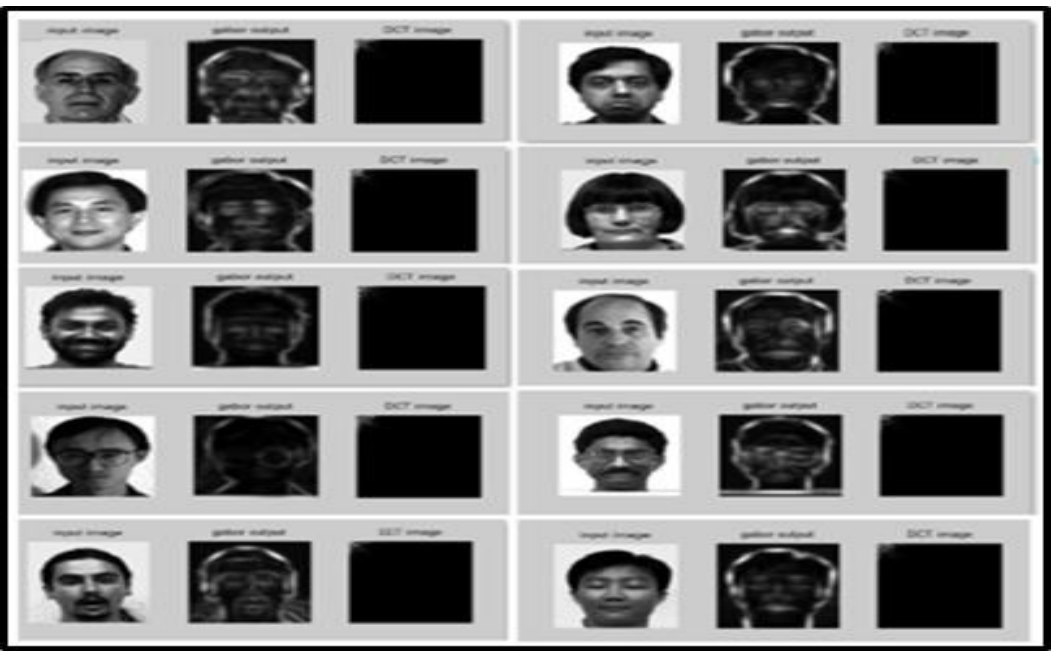

شكل (8) المعالجة الأولية بالأسلوب الثاني لعينات من صور الأشخاص

3-4 تصميم الثبكة العصبية الاصطناعية وتدريبها

تمّ استعمال كل من شبكة الاتتشار العكسي متعددة الطبقات وشبكة ايلمان العصبية[1][17][19] تمّ تكوين شبكة عصبية لكل طريقة من طرائق استخلاص الصفات المقترحة؛ وذلك للحصول على أفضل النتائج الممكنة لكل طريقة، ويمكن تلخيص الخوارزمية التي تم إتباعها في تدربب كل شبكة بالخطوات الآتية:

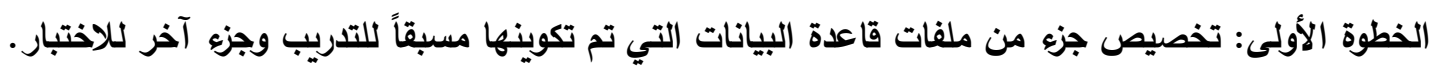
الخطوة الثانية: تكرار عملية استخلاص الصفات لجميع الصور المخصصة للتدريب وخزن متجهات التهات الصفات في مصفوفة الإدخال (p). (الخطمة

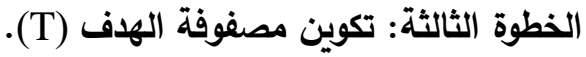
الخطوة الرابعة: تحديد العوامل المؤثرة في كفاءة تدريب الشبكة العصبية. الخطوة الخامسة: تدريب الثبكة العصبية باستعمال أزواج التدريب (P,T). الخطوة السادة: خزن الأوزان المثالية ومعاملات الثبكة في ملف التدريب؛ وذلك ليتمّ استعماله في عملية (اختبار الثبكة), والثكل(9) يوضح ذلك. 


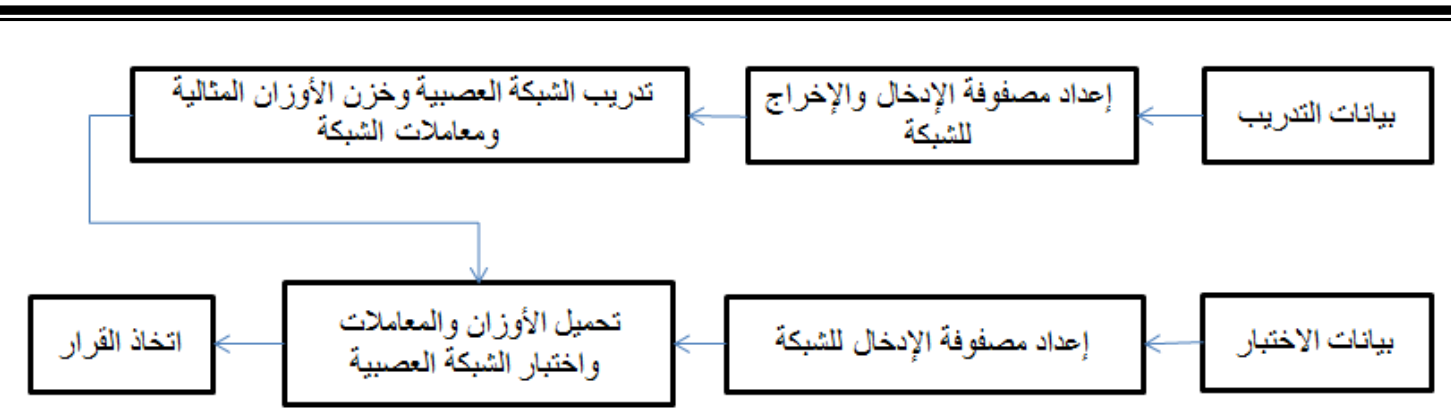

شكل(9) مخطط عام لتدريب واختبار الثبكة العصبية.

3-5 المخططات الانسيابية للخوارزميات المعتمدة

خطوات الاسلوب الاول في التمييز موضحة بالثكل(10) والذي يتضمن مخطط انسيابي متسلسل

بداء من قراءة الصور والمعالجات الاولية عليها فضلا عن استخلاص الصفات الاحصائية وانتهاءًالتمييز بالثبكات العصبية.

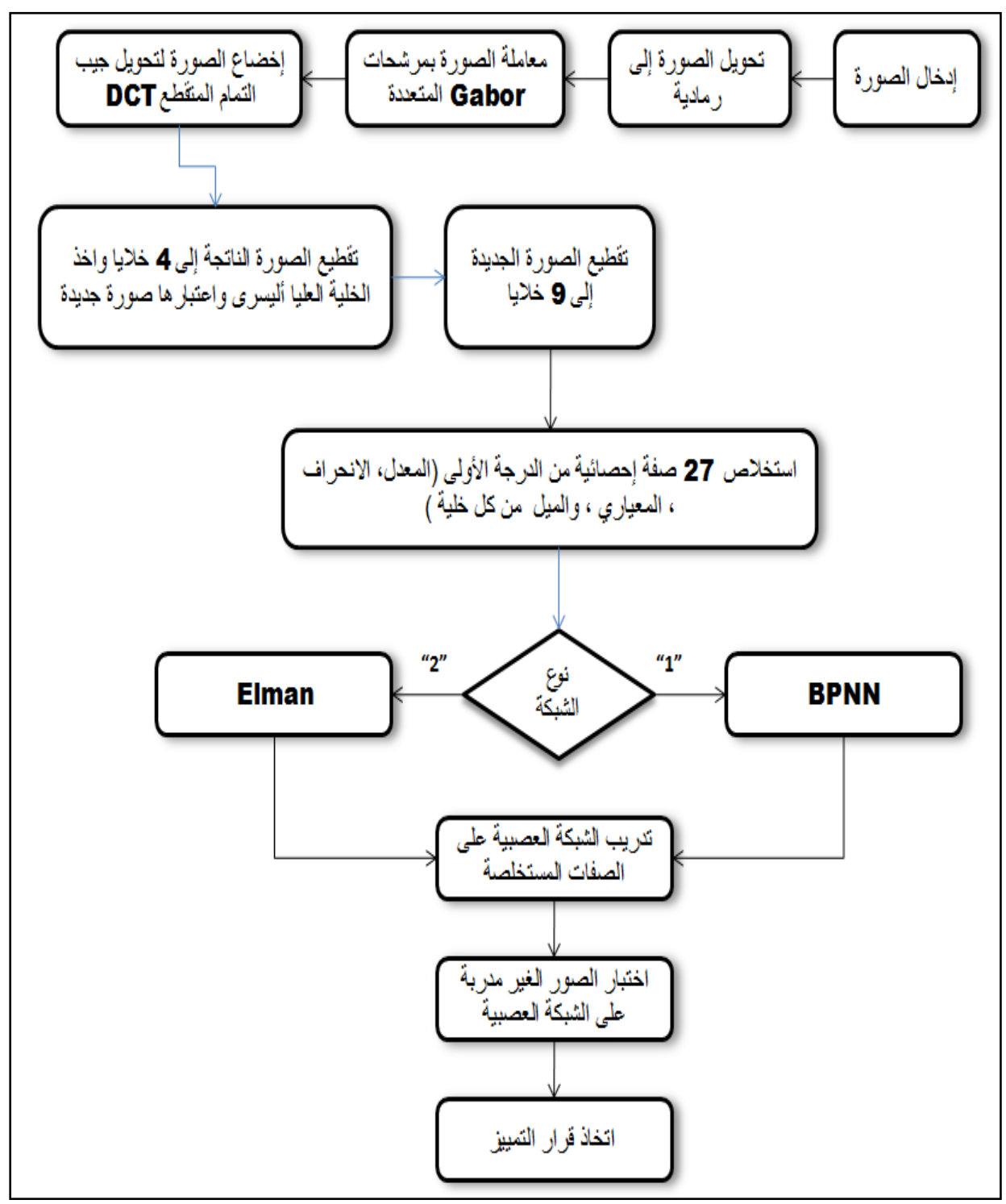

شكل (10) خطوات الاسلوب الاول في التمييز 
اما الثكل(11) يعطي خطوات الاسلوب الثاني في التمييز ابتاءً بقراءة الصور ومعالجتها المعالجات الاولية واستخلاص الصفات الاحصائية SF2 وانتهاءً بالتمييز بالثبكات العصبية.

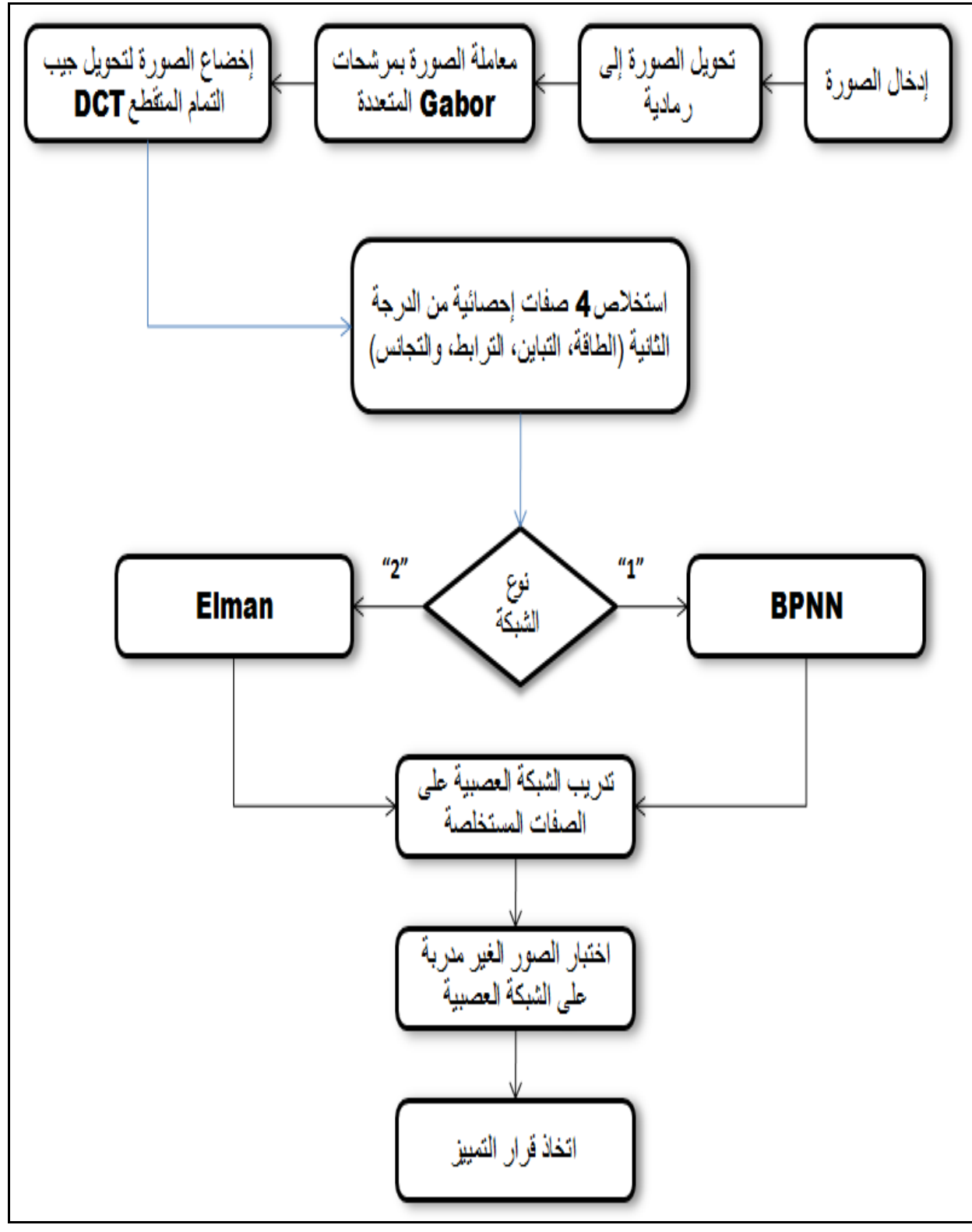

شكل (11) خطوات الاسلوب الثاني في التمييز

4-النتائج ومناقشتها

تختلف النتائج التي تم الحصول عليها من استعمال كل من شبكة الاتتشار العكسي متعددة الطبقات

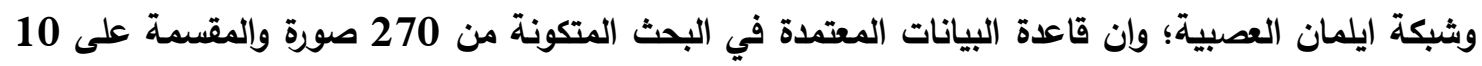
أشخاص تمثل الأصناف الرئيسية للتمييز , ويمكن ادراج اهم النتائج بالنقاط التالية:

1) بعد التجربة والتغير بين العوامل تم التوصل الى أفضل العوامل لكل من الثبكتين المستعملتين وكما موضحة في الجدول(1): 
جدول(1) العوامل المحددة في البحث

\begin{tabular}{|c|c|c|}
\hline تشبكة Elman & BPNN شبكة & المعامل/ الشبكة \\
\hline 90 & 120 & 1. عدد العقد فيالطبقة المخفية الأولى: \\
\hline 70 & 100 & 2. عدد العقد فيالطبقة المخفية الثانية: \\
\hline Logsig & Logsig & 3. دالة التششيطللطبقة المخفية الأولى: \\
\hline Logsig & Logsig & 4. دالة التششيط للطبقة المخفية الثانية: \\
\hline \multirow[t]{8}{*}{ Logsig } & Logsig & 5. دالة التنشيط لطبقة الإخر اج: \\
\hline & & 6. عدد الأشخاص: 10 \\
\hline & & 7. عدد الصور لكل شخص:27 \\
\hline & & 8. المجموع الكلي لصور قاعدة البيانات:270 \\
\hline & & 9. عدد صور التدريب لكل شخص: 22 \\
\hline & & 10. المجموع الكلي لصور التدريب:220 \\
\hline & & 11. عدد صور الاختبار لكل شخص: 5 \\
\hline & & 12. المجموع الكلي لصور الاختبار : \\
\hline
\end{tabular}

2) وان افضل النتائج الناتجة من تطبيق الطريقتينFM FMوSوضحه بالجداول(2),(3),(4),(5). فالجدول (2)نتائج الشبكتين المستعملتين BPNN و Blman

جاول(2) ملخص نتائج تطبيق شبكتي Elman وBPNN

\begin{tabular}{|c|c|c|c|c|c|}
\hline \multicolumn{2}{|c|}{ شبكة Elman } & \multicolumn{2}{|c|}{ BPNN شبكة } & \multirow{2}{*}{\multicolumn{2}{|c|}{ المعامل/ الثبكة }} \\
\hline SM & FM & SM & FM & & \\
\hline 100000 & 30704 & 100000 & 100000 & \multicolumn{2}{|c|}{ عدد الدورات الكلي } \\
\hline 0.0204 & 0.0100 & 0.00753 & 0.00772 & \multicolumn{2}{|c|}{ معدل مربع الخطأ } \\
\hline $0: 45: 15$ & $0: 13: 23$ & $0: 38: 28$ & 0:00:31 & \multicolumn{2}{|c|}{ sec. الوقت الكل لتدريب الشبكة } \\
\hline $85.0 \%$ & $95.0 \%$ & $95.5 \%$ & $95.0 \%$ & Train & \multirow{2}{*}{ نسبة الكثف الكلية } \\
\hline $80.0 \%$ & $94.0 \%$ & $92.0 \%$ & $92.0 \%$ & Test & \\
\hline
\end{tabular}

ل ويبين الجدول (3) نسب التمييز والوقت للصور الغير مدربة على الثبكات والمُعدة خصيصا للاختبار :

جدول(3) ملخص نتائج نطبيق شبكتي Blman وBPNN

\begin{tabular}{|c|c|c|c|c|c|c|c|}
\hline \multicolumn{3}{|c|}{$\begin{array}{c}\text { لتمييز الصور الغيرمدربة النلية الثبكة } \\
\text { (test images) }\end{array}$} & \multicolumn{3}{|c|}{$\begin{array}{c}\text { trained ( تمييز الصور المدربة على الثبكة } \text { (images } \\
\text { (images }\end{array}$} & \multirow[t]{2}{*}{ الثبكة } & \multirow[t]{2}{*}{ الطريقة } \\
\hline اللتمبيز الكيت sec & ن الخطبة & 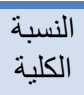 & اللتميز الوقت الكلي & الخطبة & 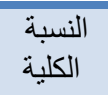 & & \\
\hline 41.5490 & $8 \%$ & $92 \%$ & 207.7150 & $5 \%$ & $95 \%$ & BPNN & \multirow[b]{2}{*}{ الطريقةالاولى } \\
\hline 41.9470 & $6 \%$ & $94 \%$ & 199.7070 & $5 \%$ & $95 \%$ & Elman & \\
\hline 39.0400 & $8 \%$ & $92 \%$ & 197.6930 & $4.5 \%$ & $95.5 \%$ & BPNN & \multirow[b]{2}{*}{ الطريقة|لثانية } \\
\hline 44.3460 & $20 \%$ & $80 \%$ & 203.2440 & $15 \%$ & $85 \%$ & Elman & \\
\hline
\end{tabular}


ومن الواضح أن شبكة BPNN قد أعطت نفس النسبة في الحالتين المتبعتين في التمييز وهي 92\% إلا أن الحالة الاولى استغرقت وقتا اكثر بقليل من الحالة الثانية, اذ كان وقتالتمييز في الحالة الاولى يساوي

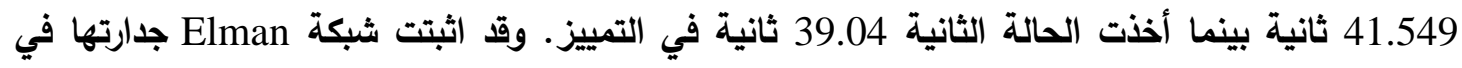
التمييز بالحالة الاولى بنسبة 94\% وبوقت يقارب ما استغرقته شبكة BPNN في الحالة نفسها, بينما تراجعت الثبكة ذاتها في التمييز بالحالة الثانية لتحصل على 80\% فقط كنسبة تمييز كلية وبوقت طويل نسبيا يصل الى ل تم ادراج نتائج التمييز لكل صنف من أصناف الصور في الجدولين (4) و (5) وبعد دراسة نتائج تمييز شبكة BPNN و SMM يُلاحظ انها قد حصلت على نسبة تمييز كلية متساوية الا انها اختلفت من ناحية الاصناف التي تمكنت من تمييزها والتي اخفقت في تمييزها بالكامل. في الحالة الاولى فيك قامت شبكة BPNN بتمييز الاصناف 9, 8, 7, 6,5,1 و بنسبة 100\% بينما أخفقت بتمييز صورة واحدة من أصل خمسة في الصنف الثاني والرابع, وصورتين من الصنف الثالث. أما في الحالة الثانية

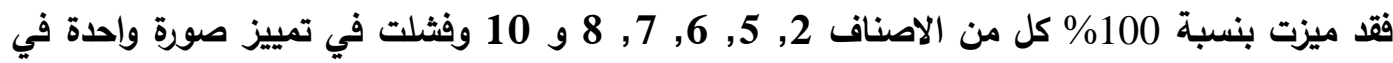
كل من الاصناف 1, 3, 4, 9.وبمعاينة نتائج تمييز شبكة Elman تبين أنها أعطت أعلى نسبة تمييز في الحالة الاولى وهي 94\% حيث ميزت بنسبة 100\% كل من الاصناف 1, 3, 5, 5, 6, 7, 8, 9 10 9 و 10 وأخفقت بتمييز صورة واحدة من الصنف الرابع وبصورتين من الصنف الثاني.

جدول(4) نتائج تطبيقFMلكل شخص

\begin{tabular}{|c|c|c|c|c|c|c|c|c|c|c|c|c|}
\hline \multicolumn{10}{|c|}{ النسب المئوية للتمييز والخطاً } & \multirow[t]{2}{*}{ Ratio } & \multirow[t]{2}{*}{ network } & \multirow[t]{2}{*}{ Data } \\
\hline الثخص10 & الثخص9 & الثخص8 & الثخص7 & الثخص6 & الثخص5 & الثخص4 & الشخص3 & الثخص2 & الثخص1 & & & \\
\hline 100 & 100 & 100 & 100 & 100 & 81.8182 & 81.8182 & 81.8182 & 81.8182 & 100 & التمييز & \multirow[t]{4}{*}{ BPNN } & \multirow[t]{2}{*}{ 220Train } \\
\hline 0 & 0 & 0 & 0 & 0 & 18.1818 & 18.1818 & 18.1818 & 18.1818 & 0 & الخطأ & & \\
\hline 100 & 100 & 100 & 100 & 100 & 100 & 80 & 60 & 80 & 100 & التمييز & & \multirow[t]{2}{*}{50 test } \\
\hline 0 & 0 & 0 & 0 & 0 & 0 & 20 & 40 & 20 & 0 & الخطأ & & \\
\hline 100 & 90.9091 & 100 & 100 & 100 & 90.9091 & 86.3636 & 100 & 81.8182 & 100 & التمييز & \multirow[t]{4}{*}{ Elman } & \multirow{2}{*}{$\begin{array}{l}220 \\
\text { Train }\end{array}$} \\
\hline 0 & 9.0909 & 0 & 0 & 0 & 9.0909 & 13.6364 & 0 & 18.1818 & 0 & الخطأ & & \\
\hline 100 & 100 & 100 & 100 & 100 & 100 & 80 & 100 & 60 & 100 & التمييز & & \multirow[t]{2}{*}{50 test } \\
\hline 0 & 0 & 0 & 0 & 0 & 0 & 20 & 0 & 40 & 0 & الخطأ & & \\
\hline
\end{tabular}

جلكل شخص SM SM (5) نتائج تطبيق

\begin{tabular}{|c|c|c|c|c|c|c|c|c|c|c|c|c|}
\hline \multicolumn{10}{|c|}{ النسب المئوية للتمييز والخطأ } & \multirow[t]{2}{*}{ Ratio } & \multirow[t]{2}{*}{ network } & \multirow[t]{2}{*}{ Data } \\
\hline الثخص10 & الشخص9 & الثخص8 & الثخص7 - ال & الثخص6 & الثخص5 & الثخص4 & 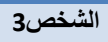 & الثخص2 & الثخص1 & & & \\
\hline 100 & 90.9091 & 100 & 100 & 100 & 100 & 81.8182 & 90.9091 & 100 & 90.9091 & التمييز & \multirow[t]{4}{*}{ BPNN } & \multirow[t]{2}{*}{ 220Train } \\
\hline 0 & 9.0909 & 0 & 0 & 0 & 0 & 18.1818 & 9.0909 & 0 & 9.0909 & الخطأ & & \\
\hline 100 & 80 & 100 & 100 & 100 & 100 & 80 & 80 & 100 & 80 & التمييز & & \multirow[t]{2}{*}{50 test } \\
\hline 0 & 20 & 0 & 0 & 0 & 0 & 20 & 20 & 0 & 20 & الخطأ & & \\
\hline 100 & 86.3636 & 50 & 90.9091 & 90.9091 & 77.2727 & 100 & 81.8182 & 90.9091 & 81.8182 & التمييز & \multirow[t]{4}{*}{ Elman } & \multirow{2}{*}{$\begin{array}{c}220 \\
\text { Train }\end{array}$} \\
\hline 0 & 13.6364 & 50 & 9.0909 & 9.0909 & 22.7273 & 0 & 18.1818 & 9.0909 & 18.1818 & 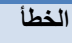 & & \\
\hline 100 & 100 & 60 & 80 & 100 & 40 & 80 & 60 & 100 & 80 & التمييز & & \multirow[t]{2}{*}{50 test } \\
\hline 0 & 0 & 40 & 20 & 0 & 60 & 20 & 40 & 0 & 20 & الخطأ & & \\
\hline
\end{tabular}

3) تصف الاشكال الاربعة (13)(13)(15)(أزمان اختبار الصور غير المدربة على الثبكات BPNN و

Elman ولكل اساليب التمييز, كل جزء من الاشكال يعطي اختلاف الاوقات اللازمة لاختبار الصورة الواحدة 


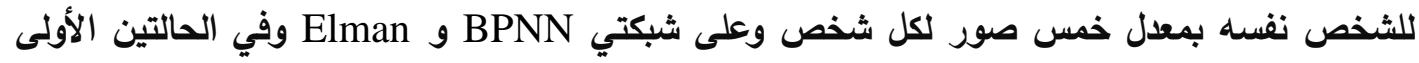

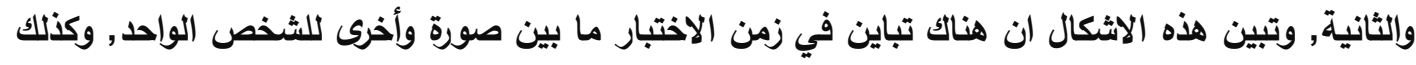

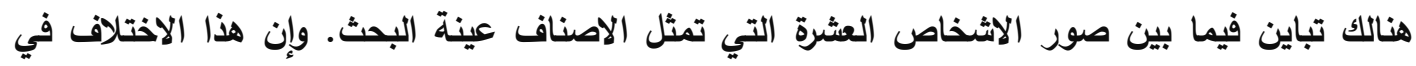

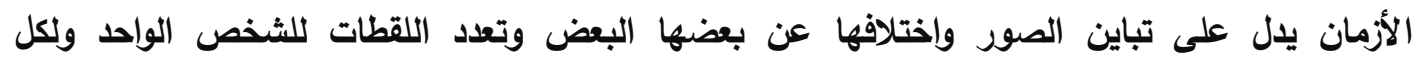
الاثخاص, مما يكثف عن قوة نظام التمييز الذي أعطى نسباً جيدة جدا رغم تباين الصور والاختلاف

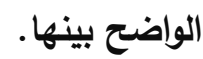

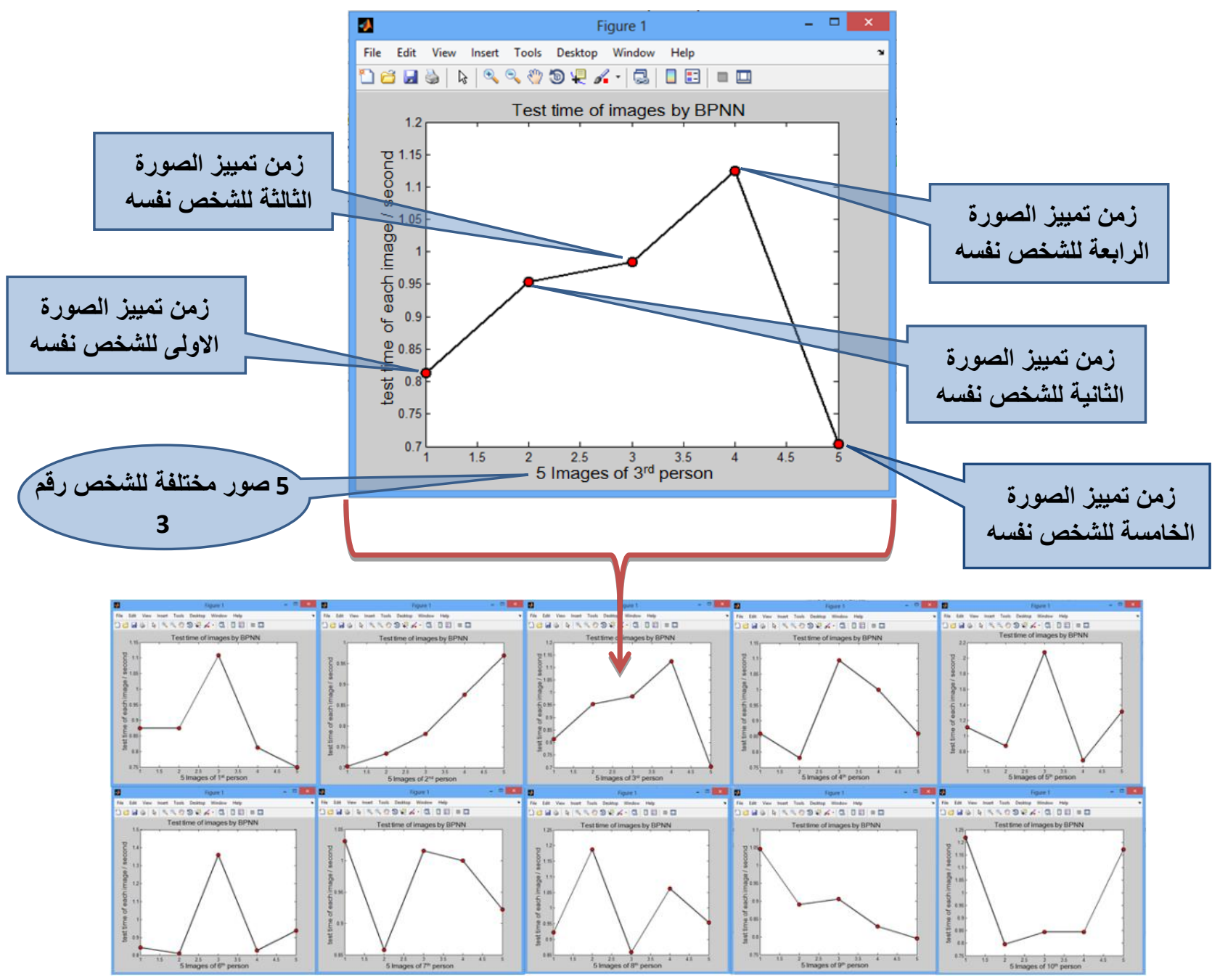

شكل(12) اختلاف زمن الاختبار فيما بين صور الثخص نفسه وما بين الاشخاص على BPNN في الحالة الاولى 


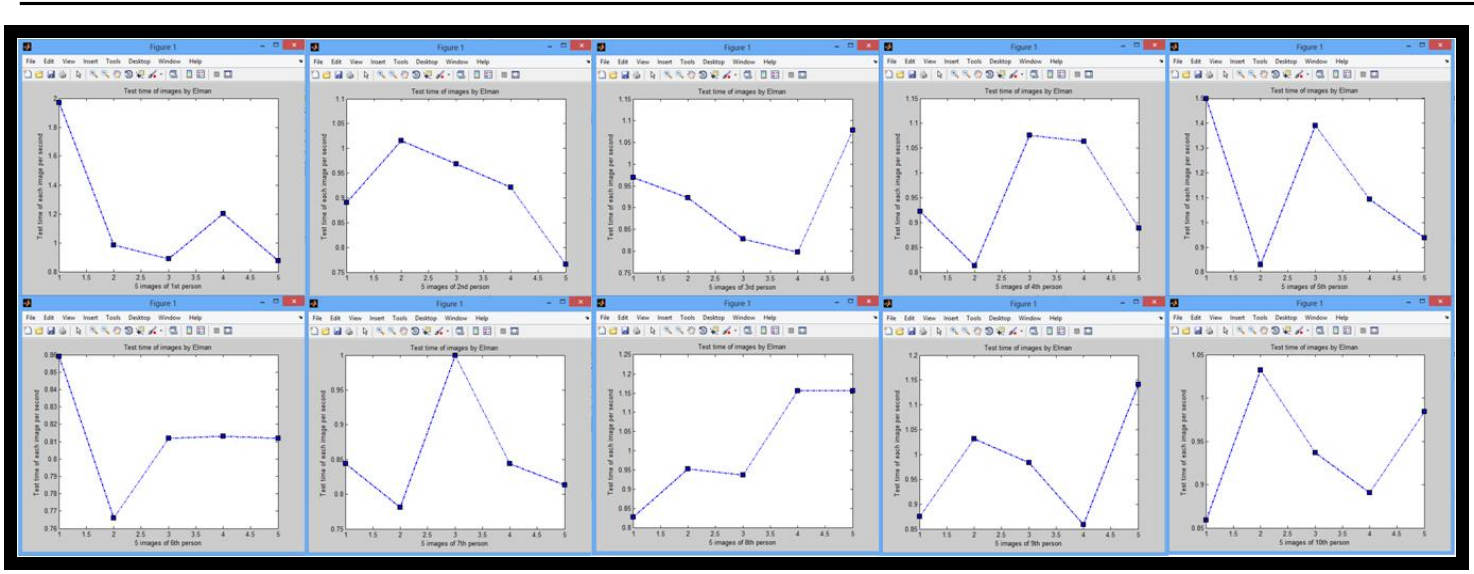

شكل (13) اختلاف زمن الاختبار فيما بين صور الثخص نفسه وما بين الاشخاص على Elman في الحالة الاولى

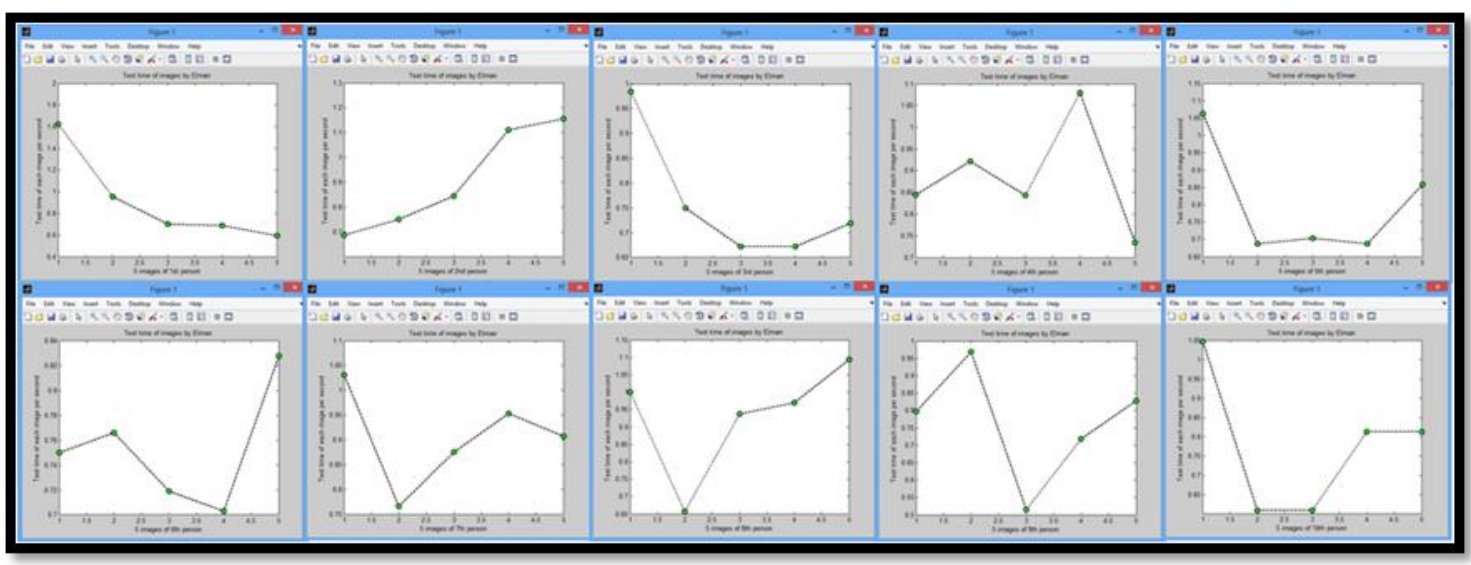

شكل (14) اختلاف زمن الاختبار فيما بين صور الثخص نفسه وما بين الاشخاص على BPNN في الحالة الثانية

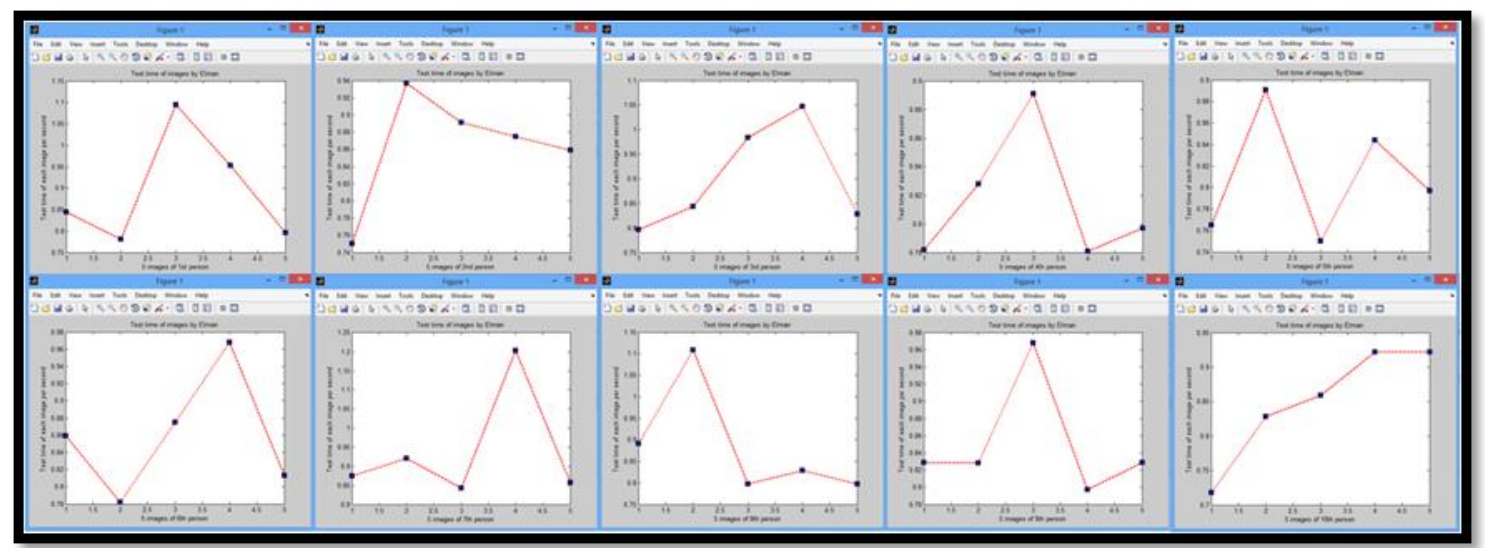

شكل (15) اختلاف زمن الاختبارفيما ابين صور الثخص نفسه وما بين الاثخاص على Elman في الحالة الثانية

4) يكشف كل جزء من الشكل (16) أربع صفات مستخلصة من خمسة صور لشخص واحد من الأشخاص

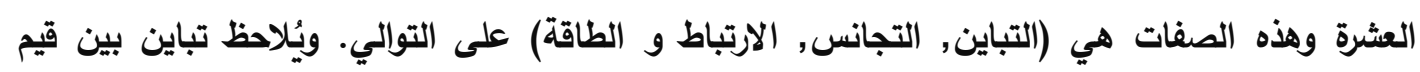

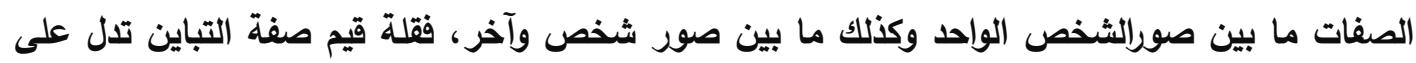

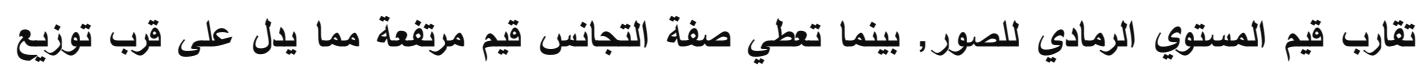

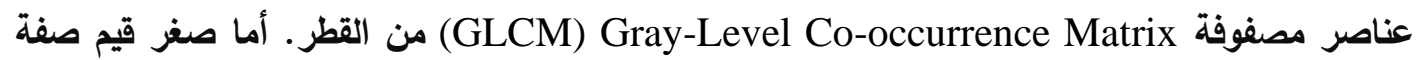


الارتباط يعطي فكرة عن عدم خطية العلاقات بين المستويات الرمادية وازواج نقاط الصورة، وأخيرا الطاقة

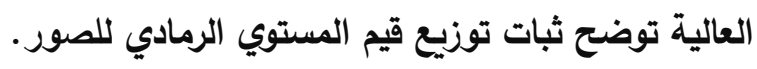

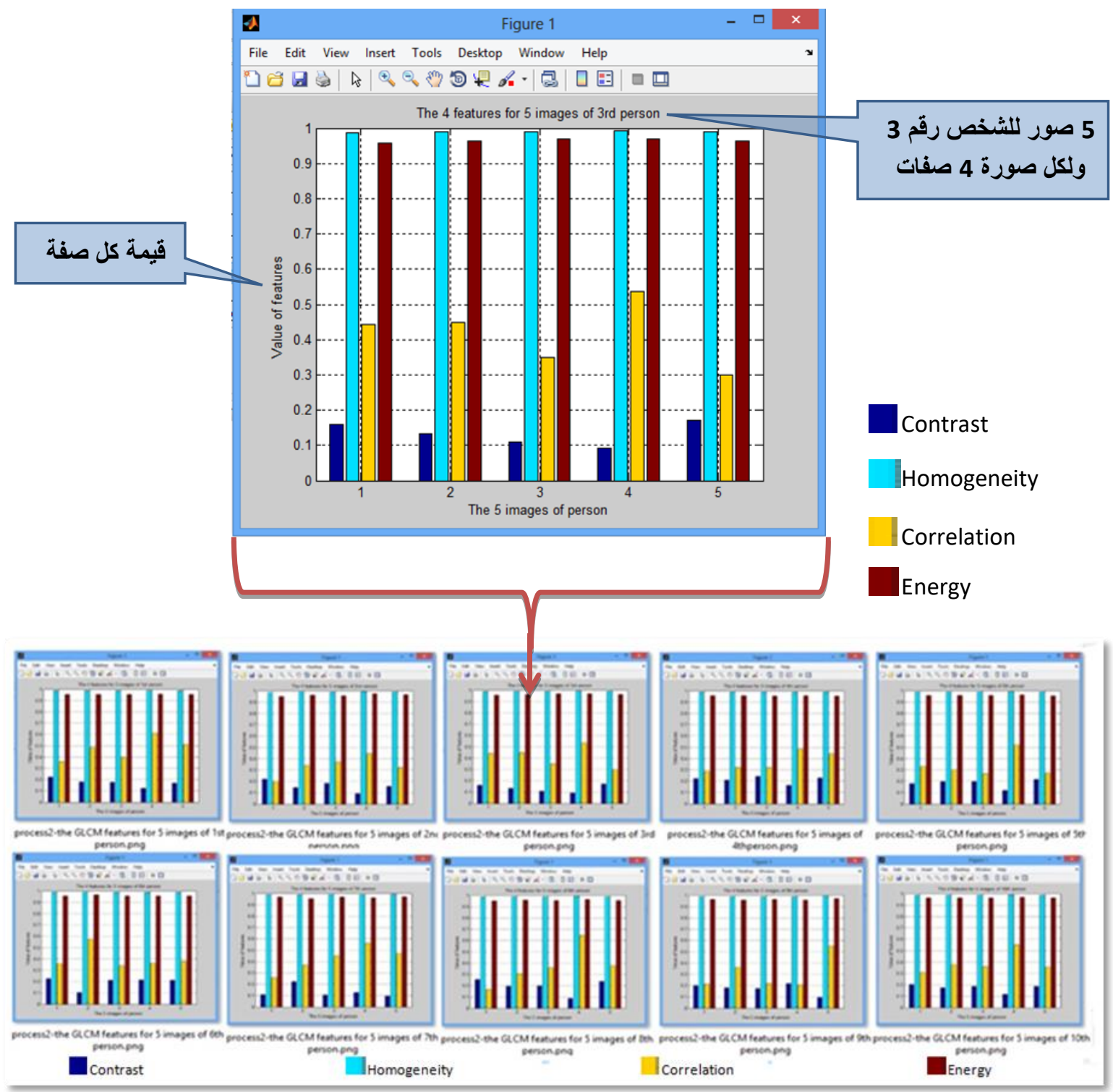

شكل(16) المخطط البيانات للصفات الإحصائية من الدرجة الثانيةSF2 المستخلصة من مصفوفة GLCM

5) من مشاهدة نسب التمييز للصور المدربة مسبقا على الثبكات يُلاحظ أن قوة الشبكات تتضح مبلئيا من تمييزها للصور المتعلمة عليها الثبكة بثكل كامل 100\% مو قريب من هذه النسبة, ومن هنا تزداد نسبة نجاح تمييز الصور المُعدة للاختبار والتي لم تتعلم عليها الثبكة. ويتجلى ذلك في الثكل (17) الذي مندي

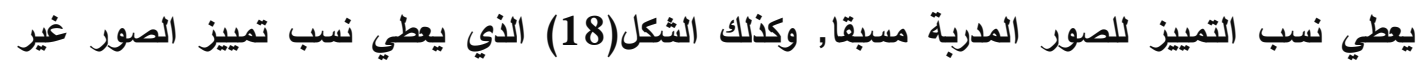
المدربة.فقد حصل الشخص العاشر P10 على نسبة 100\% للصور المدربة وغير المدربة كما حصل الثخص السادس P6 على نسب تمييز 100\% للصور المدربة ونسبة مقارنة للصورغير المدربة وفي الحالتين على حد سواء. 


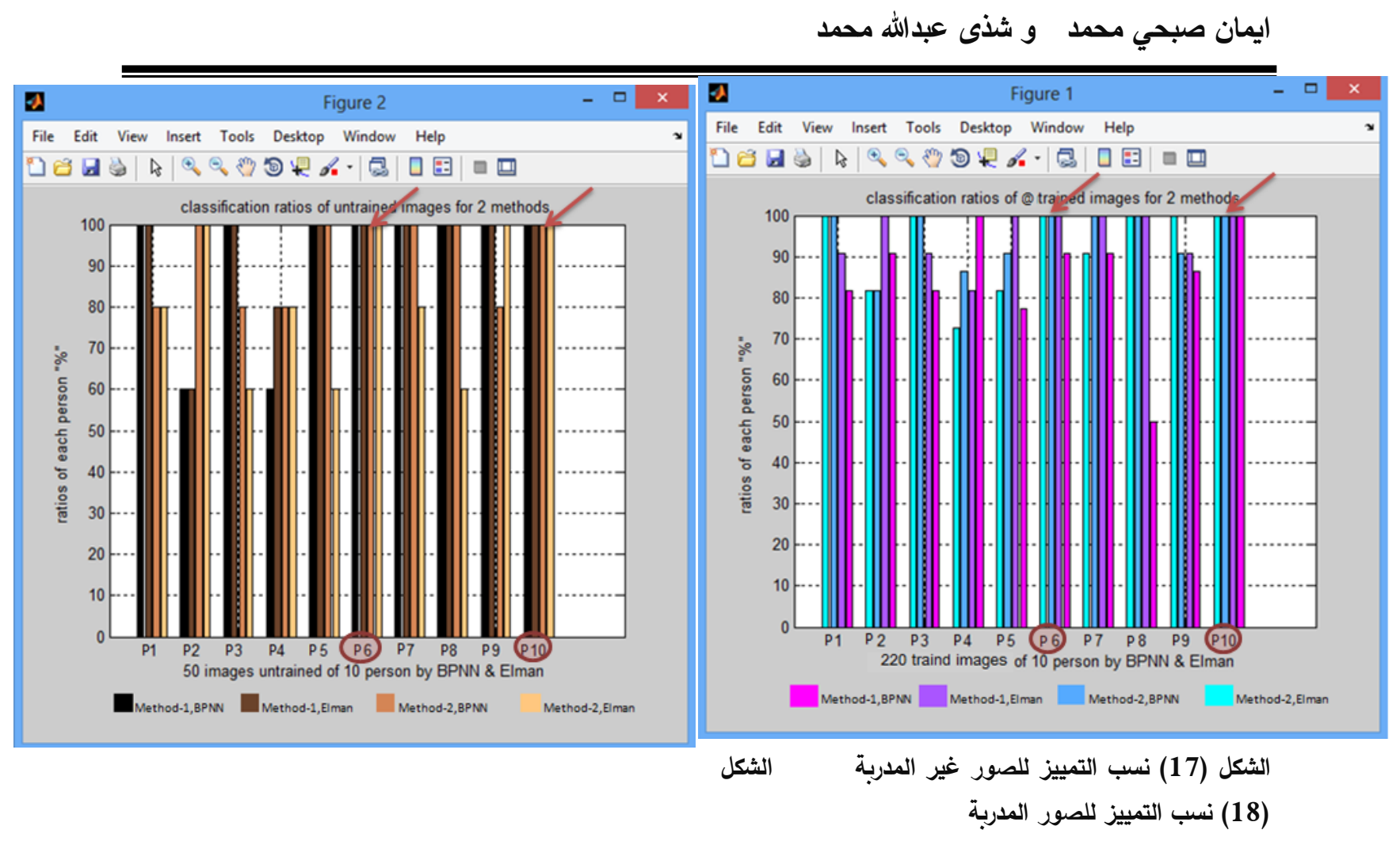

[1] Mohammed S. A. , Zidan M. A. and Hussein. M. K. , ESIT, (2017).

[2] Chetn J. , Amol B, IJSETR, (2017).

[3] Leila Z. , Réda A. , IJISA, (2017).

[4] Riddhi H. P. and Saket S. , IJARIIE, (2017).

[5] Mahajan P.M. , Kolhe S. R. and Patil P. M. , ACR 2:18-29(2009).

[6] YANG Xue Zhi Eng , PHD. Thesis, University of Technology,(2003).

[7] Revathyand G.Vidhyalakshmi P. , IJCA , 18:0975 - 8887 (2013).

[8] Xianghua X. , ELCVIA, 7:1-22 (2008).

[9] Cheng Y. and Tomas L. P. , International and Data Engineering Conference, 233243 (2000).

[10] Hassan M. Elragal, National Radio Science Conference, 14-16(2006).

[11] Arivazhagan S. , Ganesan , and Bama, L. , MVA 16(6):356-363 (2006)

[12] Zhang D. , Wong A. , Indrawan M. , Lu G. , IEEE Pacific-Rim Conference on Multimeadia, Australia:392-395 (2000).

[13] Daugman J. G. , IEEE Transaction on Pattern Analysis and Machine Intelligence, (1993)

[14] Henriksen J. J. , This report covers the theory covered and work done under the FORK part of the masters project at Syddansk Universitet, (2007)

[15] Sajid T. , and Ali B. , IOSR-JEEE 2: 33-38(2012).

[16] Jose A. L. , and Ling G. , Proceeding of IEEE International Conference on Acoustics Speech and Signal Processing, 3009-3012(1999).

[17] Mohammed I.S. and Alhamdani I. M. , (IJECE), v9:i5: 4277-4286(2019).

[18] Mohammed I.S. , AIP Conference Proceedings 2096,020005- 020005-7 (2019).

[19] Mohammed I.S.and khuder I. M. , (KUJSS), 3:529-555(2017), (In Arabic). 